\section{In der Therapie der Muskeldystrophien tut sich was!}

\author{
2013 wurde von Klymiuk et al. ein neues translationales Großtiermodell für \\ die Muskeldystrophie vom Typ Duchenne (DMD), das „DMD pig“, erstmals \\ beschrieben. Kausale Therapien seltener genetischer Erkrankungen werden \\ nun möglich.
}

G emeinsames Symptom aller Muskeldystrophien ist eine fortschreitende Muskelschwäche und -atrophie. Die DMD ist die häufigste erbliche Muskelerkrankung im Kindesalter. Vor gut 25 Jahren wurde der zugrundeliegende Defekt im Dystrophin-Gen als einer der ersten genetischen Defekte überhaupt aufgedeckt. Durch Entwicklung des DMD-Schweins lassen sich nun neue kausale Therapien genetischer Erkrankungen wie zum Beispiel das „Exon skipping" systematisch verbessern.

Bei der DMD können sogenannte Frameshift-Mutationen im DystrophinGen zur Folge haben, dass das Leseraster auf der mRNA-Ebene „ins Stottern gerät“ und der Bauplan für das Protein nicht mehr weiter abgelesen werden kann - es kommt zum vorzeitigen Abbruch der Aminosäurekette und damit fehlt dem Körper funktionstüchtiges Dystrophin. Da das Dystrophin-Gen x-chromosomal lokalisiert ist, kann bei Jungen der Verlust an Protein auch nicht über das zweite Chromosom kompensiert werden.
Das Dystrophin-Gen besteht wie eine Perlenkette aneinandergereiht aus 79 Exons - Abschnitte mit genetischer Information für den Aufbau des Proteins - getrennt durch Introns, eine Art genetisches Isoliermaterial. Die DNA wird in RNA übersetzt und diese wird gespleisst (splicing), das heißt, die Exons werden unter Herausschneiden der Introns miteinander zur messenger RNA (mRNA) verknüpft, von der die Information für das Protein abgelesen wird. Und hier lässt sich durch eine spezielle Technik, das „Exon skipping“, eingreifen: Kommt es in einem Exon durch eine Mutation zum Frameshift, kann das gestörte Leseraster durch Überspringen eines (oder mehrerer) Exons wieder hergestellt werden. Dadurch können die übrigen Exons vor und hinter dieser Stelle korrekt abgelesen und zusammengesetzt werden. Das Herausschneiden der speziellen Exone im Bereich der Mutation wird mit künstlich für diesen Bereich hergestellten speziellen RNA-Sequenzen (Antisense-Oligonukleotide) durchgeführt.
Am Ende entsteht zwar ein verkürztes, in der Funktion eingeschränktes, aber brauchbares Dystrophin; der vollständige Funktionsverlust ist aufgehoben.

$\mathrm{Zu}$ den bei Dystrophie denkbaren Therapien wie die Stammzelltherapie, die virusbasierte Gentherapie oder „Exon skipping“ gehört auch die „Stopcodon readthrough"-Therapie durch das Ende 2014 eingeschränkt zugelassene Medikament Ataluren (Translarna ${ }^{\circ}$ ). Ataluren wurde 2015 mit dem Galenusvon-Pergamon-Preis von Springer Medizin in der Kategorie „Orphan Drugs“ ausgezeichnet.

Walter MC. Update Therapie bei Muskeldystrophien. Drug Res 2015;65:S24

\section{Kommentar}

Kortikosteroide und Physiotherapie bleiben der Goldstandard der Therapie bei Muskeldystrophie vom Typ Duchenne. Der Verlust der Gehfähigkeit und respiratorische sowie kardiale Dekompensation können hierdurch leider nicht aufgehalten werden. Erfreulicherweise zielen die Entwicklungen im Bereich der personalisierten Gentherapie strategisch auf bestimmte determinierte Subtypen der Muskeldystrophien und setzen damit ein Beispiel für andere hereditäre Erkrankungen. Allerdings ist der Weg noch weit, bis diese Therapieformen Pathologie und Phänotyp der betroffenen Patienten tatsächlich zu korrigieren vermögen.

Dr. Thomas Hoppen

\section{Pilz-Epidemie in Rio de Janeiro}

Sporothrix schenckii ist Verursacher der Sporotrichose, einer subakuten oder chronischen Mykose, die alle Altersstufen befallen kann - vor allem Kinder. Seit 1998 wird in Rio de Janeiro eine echte Besonderheit mit inzwischen bedrohlichem epidemischem Verlauf dieser in Südamerika meistverbreiteten subkutanen Pilzerkrankung beobachtet. Als Überträger dieser Zoonose dienen hier interessanterweise erkrankte Katzen, die naturgemäß engen Kontakt zu kontaminiertem Schmutz und Kompost haben und den Erreger durch Kratzen und Beißen verbreiten. Die Abbildung zeigt ein typisches klinisches Bild eines seit zwei Monaten befallenen 6-jährigen Jungen.

Bei korrekter Diagnosestellung mittels Gewebekultur ist eine Langzeittherapie über 3-6 Monate mit Itraconazol $100 \mathrm{mg} / \mathrm{d}$ erfolgreich. Es gibt auch lymphokutane und bei immunsupprimierten Personen generalisierte Verlaufsformen. Als Folge des internationalen Tourismus könnten solche Patienten auch in absehbarer Zeit in unseren Praxen und Kliniken auftauchen.

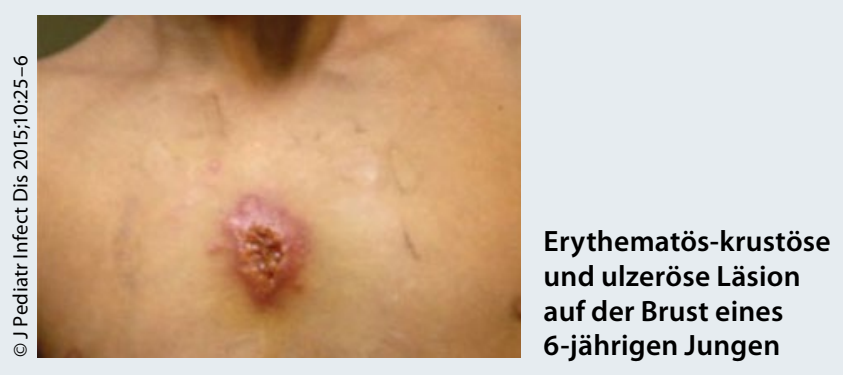

Also: Merken wir uns schon mal das Bild und fragen den potenziellen Patienten (nach der Olympiade) nach möglichem Katzenkontakt in Rio de Janeiro.

Dr. Thomas Hoppen

Ferreira CP et al. Zoonotic sporotrichosis epidemic affects children in Brazil. J Pediatr Infect Dis 2015;10:25-6 